\title{
INTERNET OF THINGS UNTUK DETEKSI LONGSOR DI DESA BANARAN KECAMATAN PULUNG KABUPATEN PONOROGO
}

\author{
Budi Artono $^{1)}$ dan Rakhmad Gusta Putra ${ }^{2)}$ \\ ${ }^{1,2}$ Teknik Elektro, Politeknik Negeri Madiun, Jl. Serayu 84, Madiun, 63133 \\ E-mail: ${ }^{1}$ budiartono@pnm.ac.id
}

\begin{abstract}
Landslide disaster that occurred in Banaran Village, Pulung Sub-district, Ponorogo Regency, in April 2017 caused many victims and left a deep wound. This disaster happened suddenly and unpredictably. Around the location there are many residents and government facilities. Landslides are difficult to detect. To be able to monitor landslides needed tools that can help provide early warning. It should be a remote control system. The Internet can be used as a medium of communication and control of equipment remotely. The advantage is its ability to connect countries and continents with low cost and relatively easy. the Internet is no longer just to connect between humans but also connect between any connected objects (the Internet of Things). Cayenne is one of the IoT (Internet of Things) platforms as well as a server that is able to store projects, supports various types of microcontrollers, user-friendly interface and has a variety of communication protocols in connecting between the microcontroller with the internet platform. This landslide hazard detection system will monitor the movement of the ground by using a processor (microcontroller), and wifi module as a data sender to be viewed and monitored on the IOT Cayenne platform through mobile phones with android operating system.
\end{abstract}

Keywords: Landslides detection, Internet of Things, Arduino, Cayenne.

\begin{abstract}
ABSTRAK
Bencana tanah longsor yang terjadi di Desa Banaran, Kecamatan Pulung Kabupaten Ponorogo pada bulan april 2017 yang lalu mengakibatkan banyak korban serta meninggalkan luka mendalam. Bencana ini terjadi secara tiba-tiba dan tanpa bisa diprediksi. Di sekitar lokasi banyak terdapat pemukiman warga dan fasilitas pemerintah. Tanah longsor termasuk sulit untuk dideteksi. Untuk bisa memantau tanah longsor diperlukan alat yang dapat membantu memberikan peringatan dini. Alat tersebut harus merupakan sistem kendali jarak jauh. Internet dapat digunakan sebagai media komunikasi dan kontrol peralatan dari jarak jauh . Kelebihannya adalah kemampuannya yang dapat menghubungkan negara serta benua dengan biaya murah dan relatif mudah. internet tidak lagi hanya untuk menghubungkan antar manusia tapi juga menghubungkan antar benda apapun yang dapat terhubung (Internet of Things). Cayenne merupakan salah satu platform IoT (Internet of Things) sekaligus sebagai server yang mampu menyimpan project, mendukung berbagai jenis mikrokontroler, interface yang user-friendly dan mempunyai berbagai macam protokol komunikasi dalam menghubungkan antara mikrokontroler dengan platform internet. Sistem deteksi bahaya longsor ini nantinya akan memantau pergerakan tanah dengan menggunakan prosesor (mikrokontroler), dan modul wifi sebagai pengirim data untuk dapat dilihat dan dimonitor pada platform IoT Cayenne melalui handphone dengan sistem operasi android.
\end{abstract}

Kata Kunci: Deteksi longsor, Internet of Things, Arduino, Cayenne.

\section{PENDAHULUAN}

Indonesia merupakan Negara yang terdiri atas banyak lembah, bukit dan gunung berapi. Setiap tahun, Indonesia banyak terjadi bencana alam tanah longsor. Tanah longsor adalah merupakan perpindahan material pembentuk lereng yang berupa batuan, bahan rombakan, tanah, atau material campuran, bergerak ke bawah atau keluar lereng. Bencana tanah longsor sering memakan korban jiwa dan harta benda. Seperti yang terjadi di Desa Banaran, Kecamatan Pulung Kabupaten Ponorogo pada bulan april 2017. Seperti dilansir oleh detikNews/detik.com Minggu 09 April 
2017, 15:26 WIB diduga kuat masih ada retakan di dalam tanah akibat hujan deras yang memungkinkan untuk terjadinya longsor susulan.

Sistem peringatan dini untuk tanah longsor di Indonesia masih sangat minim. Untuk itu, sistem peringatan dini tanah longsor dengan biaya murah dan instalasi yang mudah menjadi pilihan yang bijak dan cukup mendesak untuk segera diaplikasikan. Dengan sistem peringatan dini ini diharapkan masyarakat yang berada di lokasi rawan longsor akan lebih cepat mengetahui serta dapat memantau kondisi daerah rawan longsor sehingga akan lebih waspada terhadap kemungkinan bahaya yang datangnya tiba-tiba harapanmnya kerugian terutama korban jiwa bisa diminimalisir. Pemasangan alat peringatan dini seperti early warning system (EWS) dan Extensometer di daerah rawan lonsor jumlahnya sangat sedikit ini dikarenakan EWS biayanya mahal sekitar Rp 300 dan Extensometer sekitar Rp.100 juta

Melalui alat ini, begitu terdapat gerakan atau tanda-tanda gerakan tanah, secara otomatis dapat di pantau serta dimonitor dengan melihat secara langsung oleh semua orang dari handphone dengan O.S android di Desa Banaran, Kecamatan Pulung Kabupaten Ponorogo.

\section{METODE PENELITIAN}

Tujuan utama dari penelitian ini adalah mengembangkan internet of things untuk deteksi longsor berbasis Web. Untuk mempermudahkan mempermudah dalam merancang dan membuat suatu alat, perlu menentukan terlebih dahulu spesifikasi alat tersebut dengan memilih komponen yang akan digunakan. Beberapa komponen software maupun hadware yang digunakan, yaitu Arduino, Sensor IMU (Inertial measurement unit) , Cayenne dan Modul Wifi. Blok diagram sistem deteksi longsor ditunjukkan dalam Gambar 1 berikut.

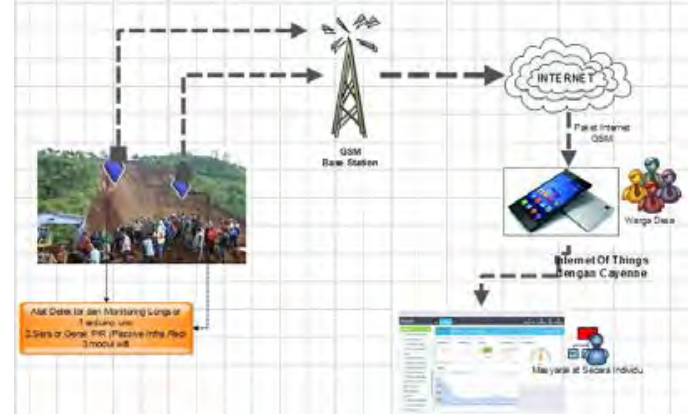

Gambar 1. Blok Diagram Sistem

Dari blok diagram sistem diatas dapat dijelaskan sebagai berikut Input Perintah Tombol digunakan untuk mengirim perintah berupa sentuhan tombol pada pada platform IoT yaitu cayenne pada handphone O.S android. Sensor Sensor IMU (Inertial measurement unit) adalah sensor yang digunakan untuk mendeteksi adanya pergerakan tanah. Modul Wifi digunakan sebagai media komunikasi antara alat ke cayenne di handphone O.S android dan arduino. Arduino digunakan ntuk memproses dan mengolah data.

Prinsip kerja dari sistem deteksi longsor ini adalah berupa sentuhan tombol pada perangkat platform IoT cayenne di handphone dengan O.S android yang digunakan sebagai alat pantau yang akan memonitor Sensor IMU yang difungsikan untuk mendeteki pergerakan tanah di daerah rawan longsor. Data tentang pergerakan tanah yang diproses oleh Sensor IMU diterjemahkan oleh mikrokontroler yang kemudian dikirim melalui modul wifi dan warga bisa mengakses dari handphone dengan paket data internet dengan login terlebih dahulu pada platform IoT yaitu cayenne. Desain sensor ditunjukkan dalam Gambar 2 berikut. Sensor mendeteksi sudut kemiringan dan kecepatan sudut yang terjadi melalui 3-Axis sumbunya. Prinsip kerja pendeteksiannya ditunjukkan dalam Gambar 3. Ketika terjadi longsor akan membuat orientasi sudut sensor terhadap gravitasi bumi berubah berikut dengan kecepatan sudut perubahannya. Ketika sensor mendeteksi nilai diatas batas maka akan dianggap sebagai kondisi tanah bergerak ataupun longsor. 


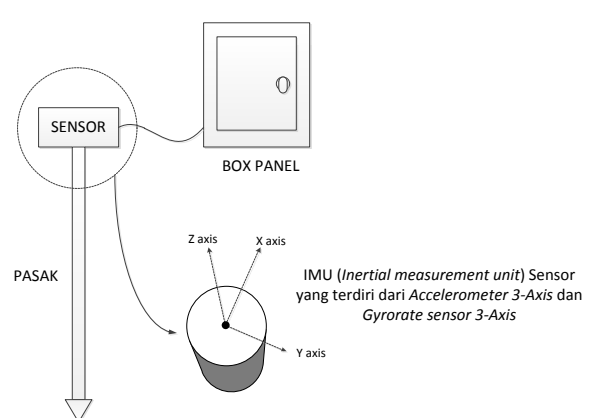

Gambar 2. Desain Sensor

Tujuan utama dipasangnya alat deteksi pergerakan tanah adalah untuk memantau adanya pergerakan tanah sehingga dapat dipantau oleh masyarakat di Desa Banaran, Kecamatan Pulung Kabupaten Ponorogo. Dengan sistem deteksi longsor dini ini maka diharapkan lokasi rawan telah bebas dari warga masyarakat saat longsor terjadi
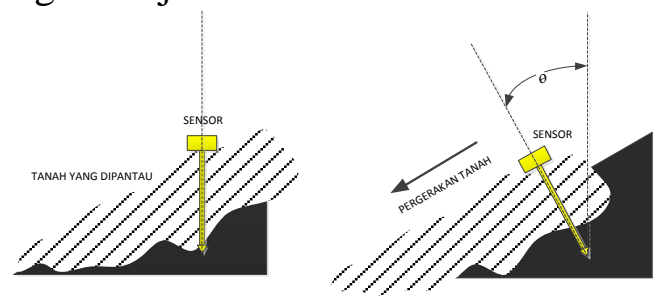

Gambar 3. Ilustrasi Prinsip Kerja Sensor

Flowchart cayenne pada sistem deteksi longsor berbasis web terdapat pada Gambar 4. Proses mulai, IP address digunakan untuk mengetahui ada tidaknya koneksi internet. Ketika sudah terkoneksi dengan internet maka button pada aplikasi cayenne bisa digunakan. Apabila button 1 ditekan Sensor IMU akan aktif dan menampilkan deteksi pergerakan tanah. Apabila sudah melakukan sentuhan pada salah satu button maka proses selesai.

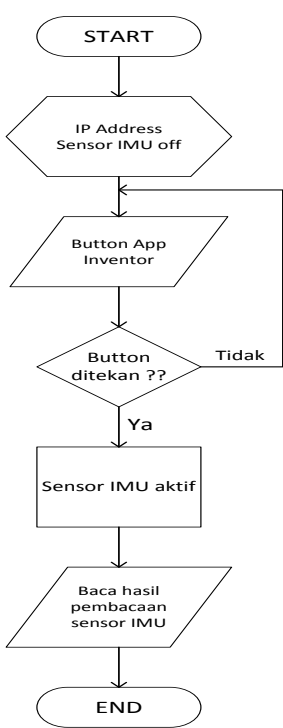

Gambar 4. Flowchart Cayenne

Flowchart arduino pada sistem deteksi longsor berbasis cayenne terdapat pada gambar 3.3. Proses mulai, inisialisasi data. Sensor IMU digunakan untuk mendeteksi apakah ada pergerakan tanah. Apabila Sensor IMU mendeteksi adanya getaran dalam skala yang besar, maka terjadi pergerakan tanah ,maka data hasil pembacaan pergerakan tanah oleh sensor akan dikirim melalui port komunikasi serial untuk ditampilkan di cayenne. Apabila Sensor IMU tidak mendeteksi adanya getaran atau mendeteksi getaran dalam skala yang kecil, maka tidak terjadi pergerakan tanah ,maka data hasil pembacaan pergerakan tanah oleh sensor akan dikirim melalui port komunikasi serial untuk ditampilkan di cayenne. Proses telah selesai di jalankan. 


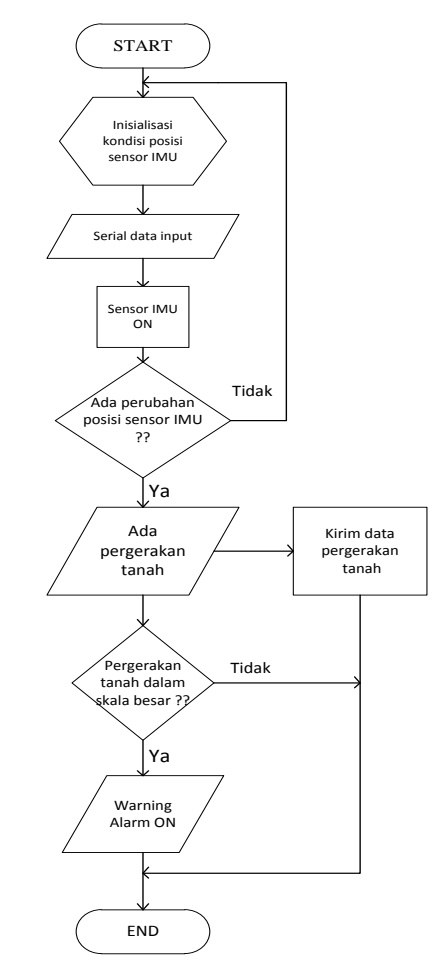

Gambar 5. Flowchart Arduino

\section{HASIL DAN PEMBAHASAN}

Berdasarkan hasil desain dan realisasi alat sistem pendeteksi longsor berbasis IoT ini dapat diuraikan menjadi beberapa penujian dan pambahasan. Penujian dan pembahasan hasil meliputi pengujian sensor, pengolahan data pada arduino, pengiriman data ke jaringan internet dan penampilan data pada Cayenne.

Realisasi alat terdiri dari dua bagian yaitu bagian sensor yang ditempatkan pada lahan yang dipantau dan panel untuk tempat rangkaian elektronika lainnya. Bagian sensor terdiri dari sensor MPU6050 gyroscope dan accelerometer, sedangkan bo panel terdiri dari arduino, perangkat IoT, baterai dan indikator sirine. Alat hasil penelitian ditampilkan dalam Gambar 6 b berikut.

Selain terdiri dari perangkat keras, sistem juga memerlukan perangkat lunak untuk menghubungkan ke internet. Dalam penelitian ini digunakan server pihak ketiga dari cayenne. Tampilan dari perangkat keras node sensor dapat diakses melalui jaringan internet baik melalui komputer maupun melalui smarthphone. Tampilan pada komputer ditunjukkan dalam Gambar 6.a berikut.

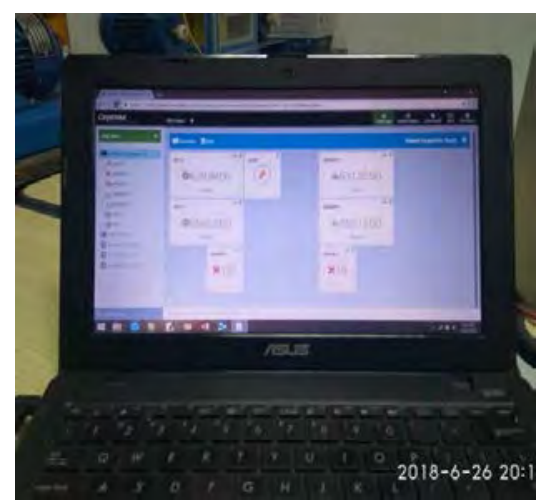

(a)

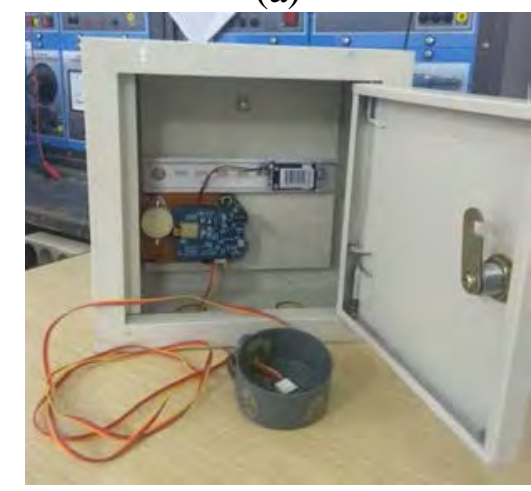

(b)

Gambar 6 (a) Tampilan Indikator Longsor dari Komputer, (b) Hasil Pembuatan Alat

Pengujian Alat dilakukan dua tahap yaitu pengujian di laboratorium dan dilakukan di lapangan. Pengujian dalam lab dilakukan dengan menguji masingmasing bagian alat. Pengujian dilanjutkan dengan pengujian pendeteksian pergerakan tanah dalam skala kecil. Pengujian ini ditunjukkan dalam Gambar 7. Pengujian dilakukan dalam kardus yang diisi dengan tanah kering kemudian sensor diletakkan diatas tanah tersebut. Bagian bawah kardus dilubangi untuk membuat tanah terjatuh kebawah pelanpelan. Dalam pengujian ini dinyatakan sistem dapat mendeteksi pergerakan tanah dengan baik.

Pengujian pembacaan sensor dilakukan untuk kesemua axis yaitu accelerometer dan gyroscope sumbu x,y dan z. Salah satu pembacaan data untuk accelerometer sb x ditampilkan dalam grafik Gambar 8 . Dalam Gambar tersebut nampak bahwa 
nilai pembacaan untuk sumbu x perlahanlahan naik. Hasil ini sebagai acuan untuk menentukan selisih kemiringan dari alat yang dibuat.
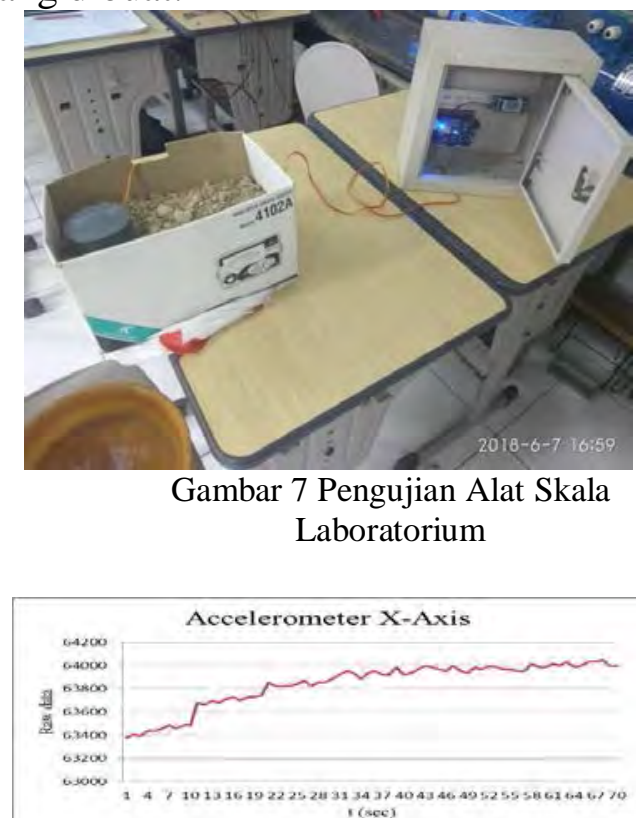

Gambar 8 Pembacaan Sensor Accelerometer untuk X-Axis( Sumber : Data primer yang diolah, 2018)

Setelah dilakukan pengujian alat skala laboratorium selanjutnya dilakukan pengujian di lapangan. Pengujian lapangan dilakukan dengan melalukan simulasi tanah longsor skala kecil. Parameter diamati adalah tingkat keberhasilan sistem terhadap kondisi pergerakan tanah. Berdasarkan pengujian didapatkan bahwa sistem telah dapat mendeteksi tanah lonsor berdasarkan perubahan kemiringan alat dan kecepat sudutnya. Foto pengujian di lapangan ditunjukkan dalam Gambar 9 berikut.

Dari pengujian keseluruh bagian alat didapatkan data seperti dalam Tabel 1 berikut. Perubahan sudut kemiringan adalah perubahan orientasi alat terhadap gravitasi disebabkan oleh pergeseran tanah. Perubahan kecepatan sudut merupakan kecepatan pergeseran tanah yang terjadi. Delay komunikasi terjadi akibat variasi kekuatan sinyal internet di lapangan. Semakin lemah sinyal maka delay akan semakin besar. Sistem telah dapat mendeteksi pergerakan tanah yang merepresentasikan tanah longsor dalam skala kecil. Sisten juga telah mampu menampilkan data melalui internet baik menggunakan komputer maupun smartphone.

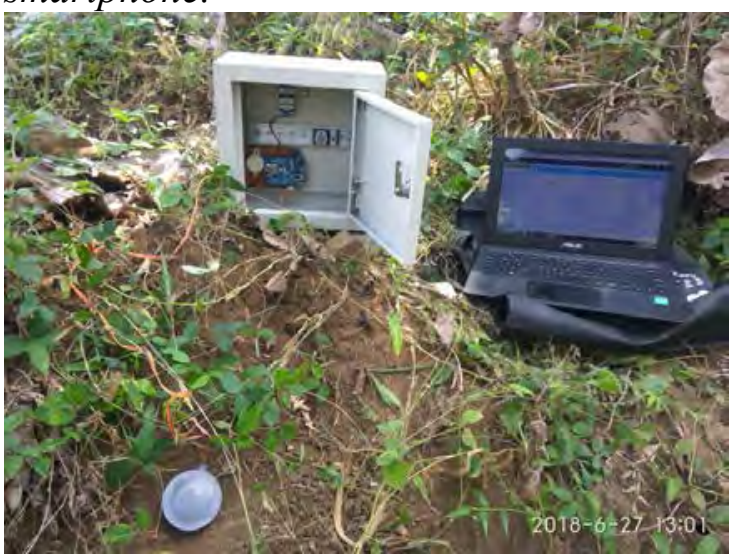

Gambar 8 Pengujian Alat di Lapangan

Tabel 1. Hasil Pengujian Alat

\begin{tabular}{lc}
\hline \multicolumn{1}{c}{ Bagian } & Nilai \\
\hline $\begin{array}{l}\text { Perubahan sudut kemiringan } \\
\text { minimum }\end{array}$ & $1^{\circ}$ \\
$\begin{array}{l}\text { Perubahan kecepatan sudut } \\
\text { Delay komunikasi }\end{array}$ & $2^{\circ} / \mathrm{sec}$ \\
$\begin{array}{l}\text { Pendeteksian longsor simulasi } \\
\text { skala lab }\end{array}$ & $\pm 2 \mathrm{sec}$ (Bervariasi berdasar kuat/ \\
$\begin{array}{l}\text { Pendeteksian longsor sinyal internet) } \\
\text { li lapangan }\end{array}$ & Berhasil \\
\end{tabular}

Indikator longsor Internet (Computer/ Smarthphone)

Sumber : Data primer yang diolah, 2018

\section{KESIMPULAN}

Berdasarkan hasil penelitian dapat diambil kesimpulan bahwa sistem telah dapat mendeteksi longsor dengan pengujian pergerakan tanah skala kecil baik tingkat laboratorium maupun lapangan dengan minimal pergeseran sudut $1^{\circ}$. Sistem juga telah dapat menampilakan data melalui internet dengan aplikasi pihak ketiga yaitu ceyenne. Delay komunikasi antara alat dengan server sangat bervariasi berdasarkan kuat lemahnya sinyal internet. Untuk pengembangan selanjutnya dapat dilakukan dengan menambahkan beberapa node sensor untuk dapat mendetaksi area yang lebih luas. Server untuk selanjutnya bisa dibangun sendiri untuk mengurangi ketergantungan alat terhadap aplikasi pihak ketiga dan meningkatkan kehandalannya. 


\section{DAFTAR PUSTAKA}

[1] Putra, R.G., \& Artono, B. (2016). Sistem kendali arah pada robot berstruktur origami dengan variasi gangguan roda berbasis gyrorate sensor. JEECAE, Vol.1 No.1, pp 1924.

[2] Artono, B. 2017. LED control system with cayenne framework for the Internet of Things (IoT), JEECAE Vol.2, No.1

[3] Sudibyo, dkk. 2015. Pendeteksi Tanah Longsor Menggunakan Sensor Cahaya. Jurnal TIM Darmajaya Vol. 01 No. 02 Oktober 2015 ISSN:24425567 | E-ISSN:2443-289X

[4] Ridho, dkk. 2015. Perancangan Deteksi Longsor Di Bukit Watu Buceng Dusun Ketos Desa Wonodadi Kulon. Jurnal Pengabdian LPPM Untag Surabaya Nopember 2015, Vol. 01, No. 02, hal $111-118$

[5] Weiser, M.: The Computer for the 21st Century. Scientific American 265(9):66-75 (1991)

[6] Asthon, Kevin. 2009. "Internet of Things”. RFID Journal, 2009.

[7] Mattern, F., Floerkemeier, C.: From the Internet of Computers to the Internet of Things

[8] Yuhefizar. 2008. 10 Jam Menguasai Internet Teknologi dan Aplikasi. Jakarta: PT.Elex Media Komputindo.

[9] Malvino, Albert Paul. 1999. Prinsipprinsip Elektronika Jilid II. Jakarta: Erlangga.

[10] Tanenbaum, AS, Computer Networks, Prentise Hall, 1996

[11] Stallings, W. Data and Computer Communications, Macmillan Publishing Company, 1985 